\title{
BMJ Open Worsening trends in self-rated health and correlates in Chinese adolescents in Hong Kong: a population-based panel study from 1999/2000 to 2014/15
}

\author{
Wei Jie Gong (D) ,1,2 Daniel Yee Tak Fong (D) , ${ }^{1}$ Man Ping Wang (D) , ${ }^{1}$ Tai Hing Lam, ${ }^{2}$ \\ Thomas Wai Hung Chung, ${ }^{3}$ Sai Yin $\mathrm{Ho}^{2}$
}

To cite: Gong WJ, Fong DYT, Wang MP, et al. Worsening trends in self-rated health and correlates in Chinese adolescents in Hong Kong: a population-based panel study from 1999/2000 to $2014 / 15$. BMJ Open 2022;12:e055842. doi:10.1136/ bmjopen-2021-055842

- Prepublication history and additional supplemental material for this paper are available online. To view these files, please visit the journal online (http://dx.doi.org/10.1136/ bmjopen-2021-055842)

Received 27 July 2021 Accepted 21 January 2022

D Check for updates

(c) Author(s) (or their employer(s)) 2022. Re-use permitted under CC BY-NC. No commercial re-use. See rights and permissions. Published by BMJ.

${ }^{1}$ School of Nursing, The University of Hong Kong, Hong Kong SAR, China

${ }^{2}$ School of Public Health, The University of Hong Kong, Hong Kong SAR, China

${ }^{3}$ Student Health Service, Department of Health, Hong Kong SAR, China

Correspondence to Dr Daniel Yee Tak Fong; dytfong@hku.hk

\section{ABSTRACT}

Objectives To examine the 15-year secular trends of selfrated health (SRH) and correlates in Chinese adolescents in Hong Kong.

Design A territory-wide population-based panel data study.

Setting Anonymised records of the annual health examination from the Student Health Service, Department of Health in Hong Kong.

Participants 397324 students in Secondary 2 (US grade 8), 335902 in Secondary 4 and 113892 in Secondary 6 during the academic year 1999/2000 and 2014/15. Outcome measures SRH and lifestyles were self-reported using standardised questionnaires. Sex-standardised and age-standardised prevalence of very poor/poor SRH and its secular annual changes across sex, grade, weight status, breakfast habits, and frequency/duration of aerobic exercises were examined. Their disparities over time were examined by interactions with the academic year in generalised estimating equations.

Results The overall prevalence of very poor/poor SRH increased from $9.3 \%$ (95\% Cl: $8.9 \%$ to $9.7 \%$ ) in $1999 / 2000$ to $15.5 \%$ (15.1\% to $15.8 \%$ ) in $2014 / 15$. Very poor/poor SRH was more prevalent in girls (adjusted OR: 1.02), in those having unemployed parents (1.29), being overweight (1.42) or obese (2.62), eating breakfast away from home (1.27) and skipping breakfast (1.49) or doing $<1$ time/week or $\leq 60 \mathrm{~min} /$ week aerobic exercises (1.78 and 1.88, respectively) than others. The corresponding disparities increased over time (ratios of OR: 1.006-1.042).

Conclusions Increasing prevalence of very poor/poor SRH from 1999/2000 to 2014/15 was found among Hong Kong Chinese adolescents, which was greater in girls, adolescents being overweight/obese and those having unemployed parents or unhealthy lifestyles. Strategies to reduce health inequality should consider multiple factors, especially modifiable factors including lifestyles.

\section{INTRODUCTION}

Self-rated health (SRH) is a multidimensional concept of health and an independent predictor of health status, quality of life, healthcare utilisation and future mortality. ${ }^{12}$ Respondents usually rate their own overall health based
Strengths and limitations of this study

- This study used the large representative annual health assessment records of Hong Kong secondary school students.

- Territory-wide population-based panel data were used to elicit the 15-year secular trends of self-rated health among Hong Kong adolescents.

- The validity of self-reported lifestyle measures may be limited due to recall and reporting biases.

- No causal inference could be made in this panel study.

on health status, general physical function and health-related behaviours. ${ }^{3}$ Although adolescents generally have better physical health status than adults and older people, their SRH was not found to be far better than that of others. ${ }^{4}$ Adolescents tend to rate their health more on personal, socio-environmental, behavioural and psychological factors. ${ }^{5}$ Demographic characteristics, socioeconomic factors, lifestyle behaviours and mental health status have been reported to be correlates of their SRH. ${ }^{5}$ Adolescents with favourable socioeconomic characteristics usually show higher SRH, and the inequalities can be directly and indirectly affected by psychosocial and behavioural factors. ${ }^{6}$

Good SRH enables adolescents to face the challenges in their transition to adulthood. ${ }^{7}$ From the public health perspective, trends in adolescent SRH can help to track changes in population health and social and cultural health influence. ${ }^{8}$ We searched PubMed and Web of Science until 25 February 2021 and only found such trend studies from the West. In 32 European countries, adolescent SRH generally improved during 2002/10, but the proportion of excellent SRH was lower during 2006/10, reflecting the socioeconomic difficulties in Europe during this period. ${ }^{9}$ In Nordic countries, SRH generally 
had a slight and gradual improvement during 2002/06 but then remained stable until 2014, which coincided with the global economic recession in 2007/08 ${ }^{10}$ Correlates of the trends in adolescent SRH could be used to facilitate more targeted attention and assistance to prevent worsening SRH in vulnerable groups. However, this had not been pursued in the literature.

Adolescence is a crucial period for the formation of lifestyles and perception of health, ${ }^{5}$ during which lifestyles are modifiable factors of subjective health and can maintain in later life, including physical activity and dietary habits. ${ }^{61112}$ Interventions to improve physical activity and diet were found to be cost-effective in adolescents. ${ }^{13}$ Widely accepted as the most important meal of the day, breakfast provides essential nutrients and energy for adolescents' growing body after fasting overnight but is the meal most often missed. ${ }^{14}$ Poor breakfast habits may cause micronutrients deficiency which may not be compensated for in other meals and thus may affect children's and adolescents' psychosocial health. ${ }^{15} 16$ Eating breakfast away from home and skipping breakfast were found to predict more emotional and behavioural problems in Chinese adolescents, while eating breakfast at home were beneficial. ${ }^{17}$ Whether these modifiable lifestyles are associated with trends in adolescent SRH is still unknown.

Unlike multi-ethnic Western settings, Hong Kong, the most westernised city in China, has a relatively homogeneous ethnic Chinese population (around 92.0\% in $2016),{ }^{18}$ with a relatively recent history of rapid socioeconomic development over a few decades. ${ }^{19}$ During such a period, adolescents in Hong Kong had experienced rapid social changes and better living conditions during their growth development, which influenced their lifestyles and health indicators. Therefore, Hong Kong adolescents could be an ideal population group to examine health-related trends and disparities during adolescence for informing healthcare policies in other countries and regions with short but rapid economic development, including the rest of China and other regions of Asia. This study aimed to examine the secular trends in adolescent SRH and its associated factors, including sex, age, socioeconomic status, lifestyles and weight status in Hong Kong adolescents.

\section{METHODS}

\section{Design and subjects}

This panel study was territory-wide and populationbased. Participants were students studying in Secondary 2 (S2 or US grade 8), Secondary 4 (S4) and Secondary 6 (S6) who attended the Student Health Service (SHS) of the Department of Health during the academic years of $1999 / 2000$ to $2014 / 15$ (2009/10 excluded) in Hong Kong. The SHS provided voluntary free annual health assessments for all primary and secondary school students in 12 SHS centres, which covers all Hong Kong regions. According to the location of attending school, students would be given an annual appointment and have the health exanimation at a designated SHS centre. In 2009/10, S2-S6 students did not attend the assessments because the SHS had to take part in the Human Swine Influenza Vaccination Programme. From 2011/12 to 2014/15, S2 students were not required to complete the questionnaires.

Each student had a unique identification number, but all data were anonymously collected. ${ }^{20}$

\section{Measurements}

Dependent variables

Each student completed a self-administered health assessment questionnaire with 27 close-ended questions on their health-related status or behaviours. SRH was assessed in S2, S4 and S6, using the single item "Regarding my health status, I think I am ..." with four response options of 'very poor', 'poor', 'fair' and 'good or very good'. It was dichotomised as very poor/poor (very unfit/unfit) versus others.

\section{Independent variables}

Lifestyles were assessed in S2, S4 and S6 by a set of closedended items. Breakfast habit was assessed by the item "I usually have breakfast at..." with four response options: (i) 'no breakfast at all' denoted skipping breakfast, (ii) 'home' denoted eating at home, (iii) 'fast-food stall/cafeteria/restaurant' and (iv) 'some other places' denoted eating breakfast away from home. The frequency and duration of extracurricular aerobic exercises, including ball sports, swimming, running, etc, were dichotomised as $<1$ or $\geq 1$ time/week and $\leq 60$ or $>60 \mathrm{~min} /$ week, respectively.

Information of sex, age, weight, height and socioeconomic status was also collected from SHS. Weight (to the nearest $0.1 \mathrm{~kg}$ ) and height (to the nearest $0.1 \mathrm{~cm}$ ) were annually measured by well-trained healthcare staff following standard procedures. Socioeconomic status was reported by children's parents/guardians when each child first participated in the examination, including parental educational level (primary or below, secondary and tertiary) and parental occupation (unemployed, manual job, clerical/service industry and managerial/ professional job) in terms of the highest status of parents. Body mass index (BMI) $\left(\mathrm{kg} / \mathrm{m}^{2}\right)$ was calculated as weight $(\mathrm{kg})$ divided by squared height $\left(\mathrm{m}^{2}\right)$. Weight status was classified as underweight, normal, overweight and obese using sex-specific and age-specific BMI cut-offs of the International Obesity Task Force standards, which correspond to BMI values of $18.5,25.0$ and $30.0 \mathrm{~kg} / \mathrm{m}^{2}$ at 18 years of age. ${ }^{21}$ Details of the methods have been reported elsewhere. $^{22}$

\section{Statistical analysis}

Students having data of SRH records in S2, S4 or S6 were included in this analysis. To examine whether the included students were representative for all the 
corresponding enrolled SHS participants, Cramer's $\mathrm{V}$ was used as the effect size for categorical characteristics to examine the extent of differences between the included and excluded students. Small, medium and large effect sizes were defined by Cramer's V taking values of $0.10,0.30$ and 0.50 , respectively. ${ }^{23}$ To reduce the bias caused by different sex and age distributions over academic years, all percentages were sex-standardised and age-standardised using the corresponding enrolled Hong Kong students in 2018/19. ${ }^{24}$ Cochran-Armitage trend test was used to assess the trends in the prevalence of very poor/poor SRH over academic years. The annual percentage change (APC) of prevalence with 95\% CIs was calculated using linear models with the regression term of academic years.

Since some students had repeated measurements in S2, S4 and S6 or repeated a study grade in different academic years, there could be correlation (extracovariance) of such repeated measurements. To account for the corresponding effects, we used generalised estimating equations (GEE) with a logit link to examine how the trends in very poor/poor SRH were associated with different characteristics, including sex, study grade, parental educational level and occupation, weight status, breakfast habits and frequency and duration of aerobic exercises. The GEE models accounted the extra-covariance among repeated measurements over time by a working correlation matrix of the repeated measurements. Note that an identity working correlation matrix assumed all measurements were independent, and we used an unstructured working correlation matrix to allow any degree of associations among the repeated measurements. For every one-unit increase in these characteristics, GEE estimate the corresponding average changes of the outcomes. ${ }^{25}$ Two groups of GEE models were used. Model I examined the associations of academic years and the above-mentioned characteristics with very poor/poor SRH. Adjusted ORs (AORs) for academic years were calculated to examine the general trends in SRH over academic years, with the value $>1$ indicating increasing percentages in subgroups compared with the reference subgroup. To examine whether the associations between characteristics with very poor/poor SRH changed over time, model II additionally included the interaction terms of these characteristics with academic years. The ratio of ORs (RORs) for the interaction effects were calculated to examine whether the disparities changed over time, with the value $>1$ indicating increasing disparities. For example, the ROR for the interaction of sex with academic years were calculated using the OR of academic year in female being divided by the OR of academic year in male. The calculated ROR $>1$ indicates that female have a faster change than male, showing as an increasing disparity. All analyses were conducted in the Statistical Analysis System (SAS
Institute, Cary, North Carolina, USA) V.9.4, and a twotailed $\mathrm{p}$ value $<0.05$ was considered to be statistically significant.

\section{Patient and public involvement}

Patients and/or the public were not involved in the design, or conduct, or reporting, or dissemination plans of this research.

\section{RESULTS}

From the academic year of $1999 / 2000$ to $2014 / 15$, totally 548186 students in S2, 340161 in S4 and 115377 in S6 were extracted from the SHS database. The overall enrolment rate of SHS service was $85.0 \%$ of Hong Kong primary and secondary school students during the study period. ${ }^{26}$ After excluding those having no records of SRH in S2, S4 or S6, $397324(72.5 \%)$ records in S2, 335902 $(98.7 \%)$ in S4 and 113892 (98.7\%) in S6 were included in this study. All differences of the characteristics between the included and excluded students were small, with all Cramer's V $\leq 0.08$ (online supplemental table 1).

Table 1 shows that students were aged around 14, 16 and 18 years in S2, S4 and S6, respectively. There were more girls than boys across all academic years. From 1999/2000 to $2014 / 15$, the sex-standardised and age-standardised percentages of children having tertiary or above educated parents increased from $9.5 \%$ to $20.9 \%$, having primary or below educated parents decreased from $22.4 \%$ to $8.7 \%$, having parents with manual jobs decreased from $44.8 \%$ to $29.6 \%$ and being overweight and obese slightly increased from $9.8 \%$ and $1.8 \%$ to $10.7 \%$ and $2.5 \%$, respectively.

During the study period, the overall prevalence of very poor/poor SRH remained steady at $9.3 \%-9.7 \%$ from $1999 / 2000$ to $2002 / 03$ and then increased to $15.5 \%$ (95\% CI $15.1 \%$ to $15.8 \%$ ) in $2014 / 15$ (online supplemental table 2), corresponding to APC of 0.46 (95\% CI 0.33 to 0.59$)$.

Figure 1 shows that very poor/poor SRH were more prevalent in girls, those in higher grades, having primary or below educated parents, having parents with manual occupations or unemployed parents, being underweight, overweight or obese or having unhealthy lifestyles, including eating breakfast away from home or skipping breakfast and doing aerobic exercises for $<1$ time/week or for $\leq 60 \mathrm{~min} /$ week. Adolescents in these subgroups had higher odds of very poor/poor SRH than their peers (model I in table 2: all corresponding AORs $\geq 1.02, p \leq 0.03$ ).

Results of model II in table 2 show that, although very poor/poor SRH increased over time in all subgroups (all AOR of academic year $\geq 1.02, \mathrm{p}<0.001$ ), increasing disparities were found for sex, between adolescents with unemployed parents and those with managerial/professional occupation, between those being overweight/obesity and those having normal weight, between those eating breakfast away from home or skipping and those eating at home and between those doing aerobic exercises for $<1$ time/week or for $\leq 60 \mathrm{~min} /$ week and those doing less (all 


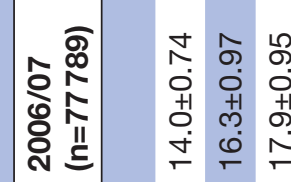

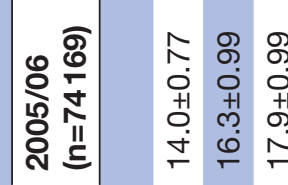

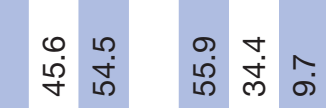

ำำำ

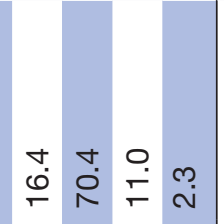

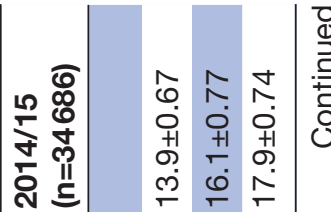

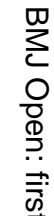

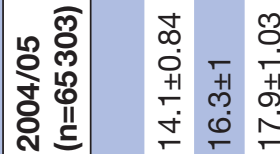

过品

它 恼

○) $\infty$

๘)

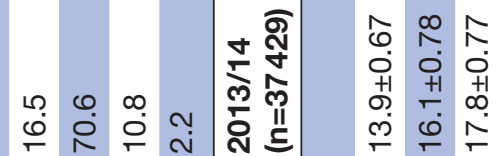

$\frac{\overline{0}}{\frac{0}{\overline{0}}}$

$\vec{\circ}$

$\vec{\omega}$

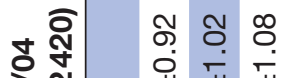

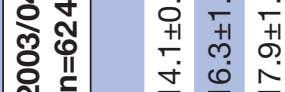

do

กั $\stackrel{\square}{\square}$

ஒே户்

Г⿸户㔾

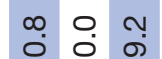

ํำ

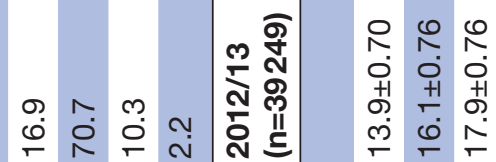

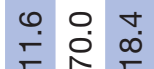

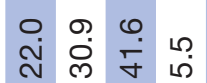

ง สํำำ

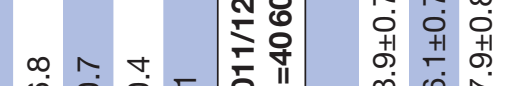

लํ

$\frac{\omega}{\frac{5}{\pi}}$

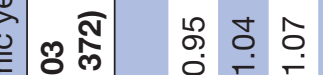

จิ

.

จิ

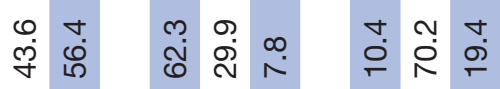

ลี

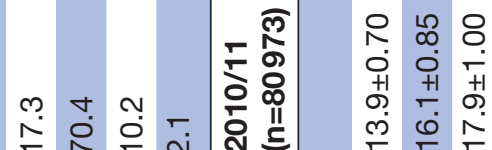

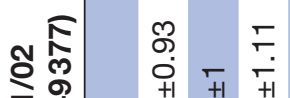

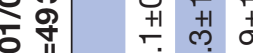

오 II

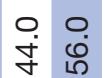

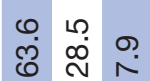

ำ

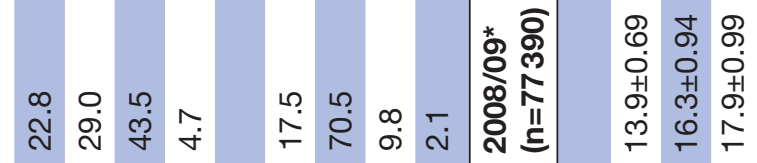

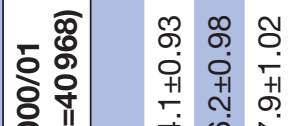

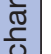

突

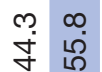

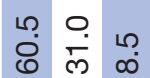

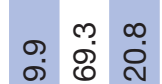

นึ่

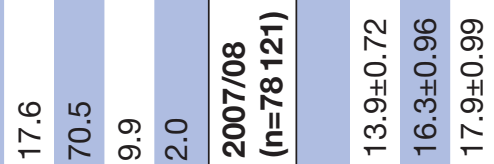

ช จ क मे

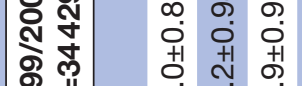

政

进

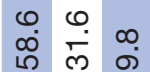

مீ

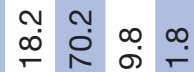




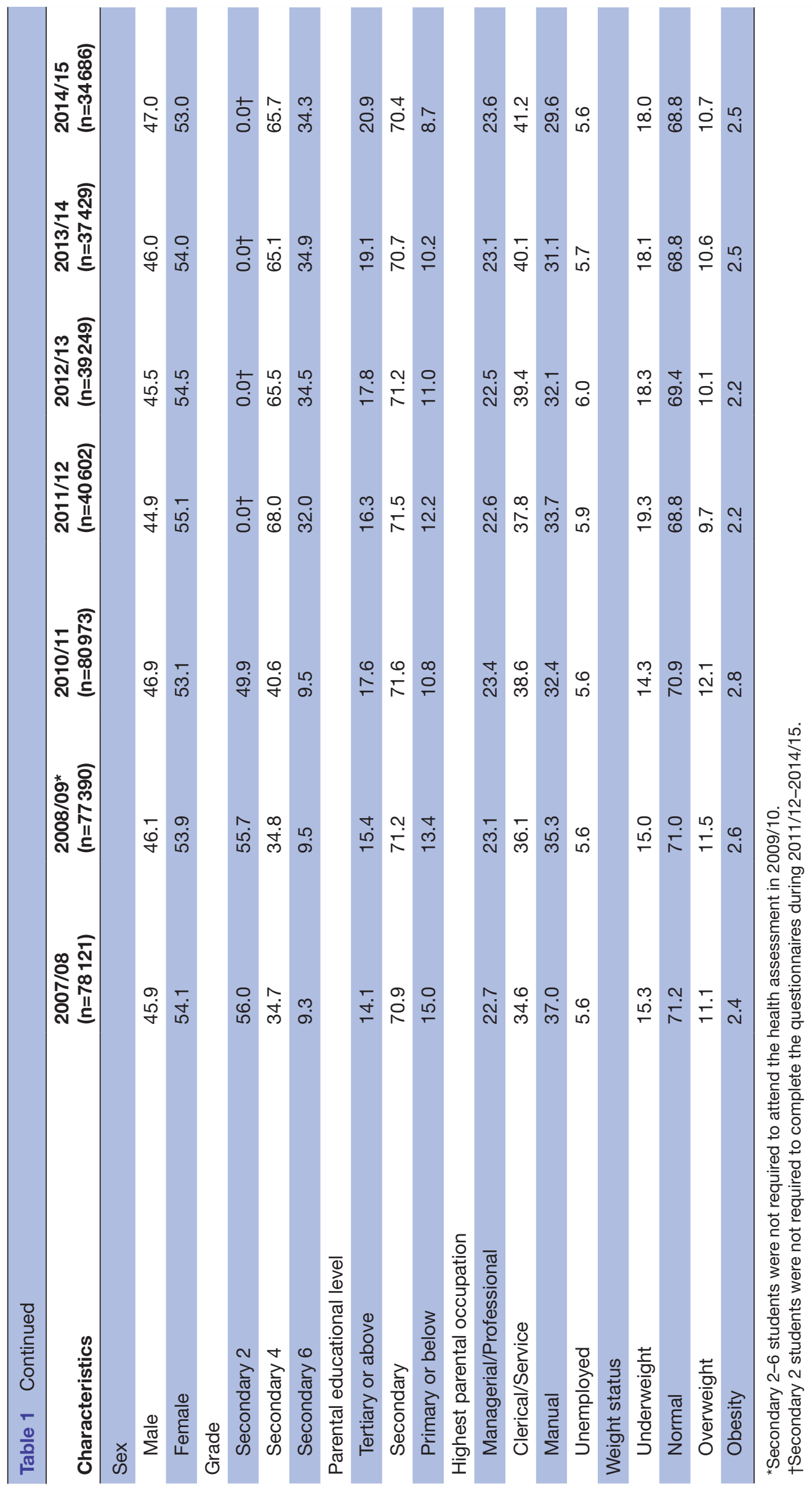



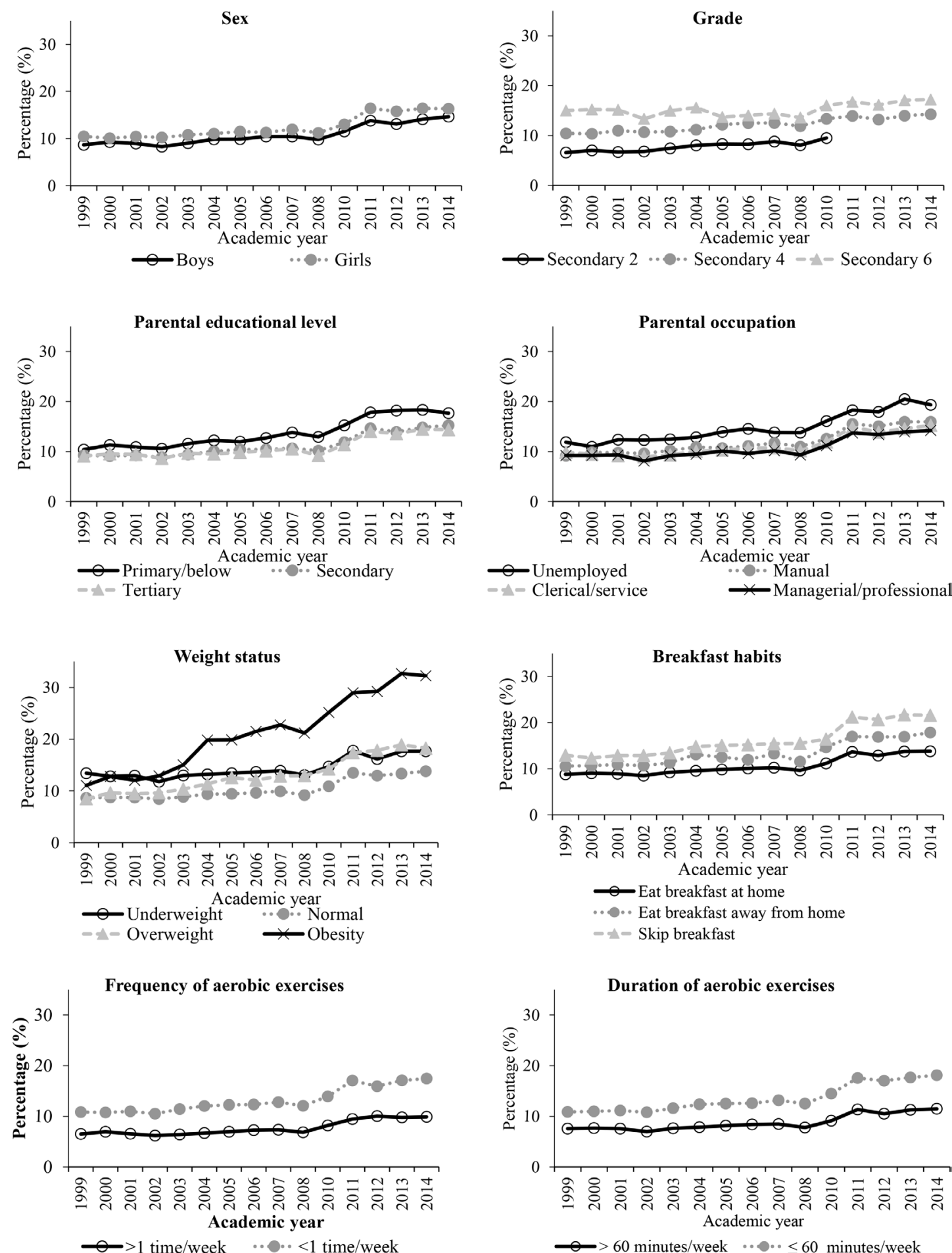

Figure 1 Sex-standardised and age-standardised prevalence of very poor/poor self-rated health by different characteristics.

RORs 21.006 ), while decreasing disparities were found for grades and between those being underweight and those having normal weight $(\mathrm{ROR} \leq 0.989)$.

\section{DISCUSSION}

This study was the first to report the worsening trends in SRH in Asian adolescents. Chinese adolescents in Hong Kong showed an increasing prevalence of very poor/ poor SRH from 1999/2000 to 2014/15. The increase was greater in girls and adolescents having unemployed parents, being overweight or obese, having unhealthy breakfast habits or having less frequent or duration of aerobic exercises.

The worsening trends of adolescent SRH in Hong Kong could be an alarm of worsening population health. Benefited from the large improvement in living conditions, medical science and clinical technology, the life expectancy for the Hong Kong population was the longest in 


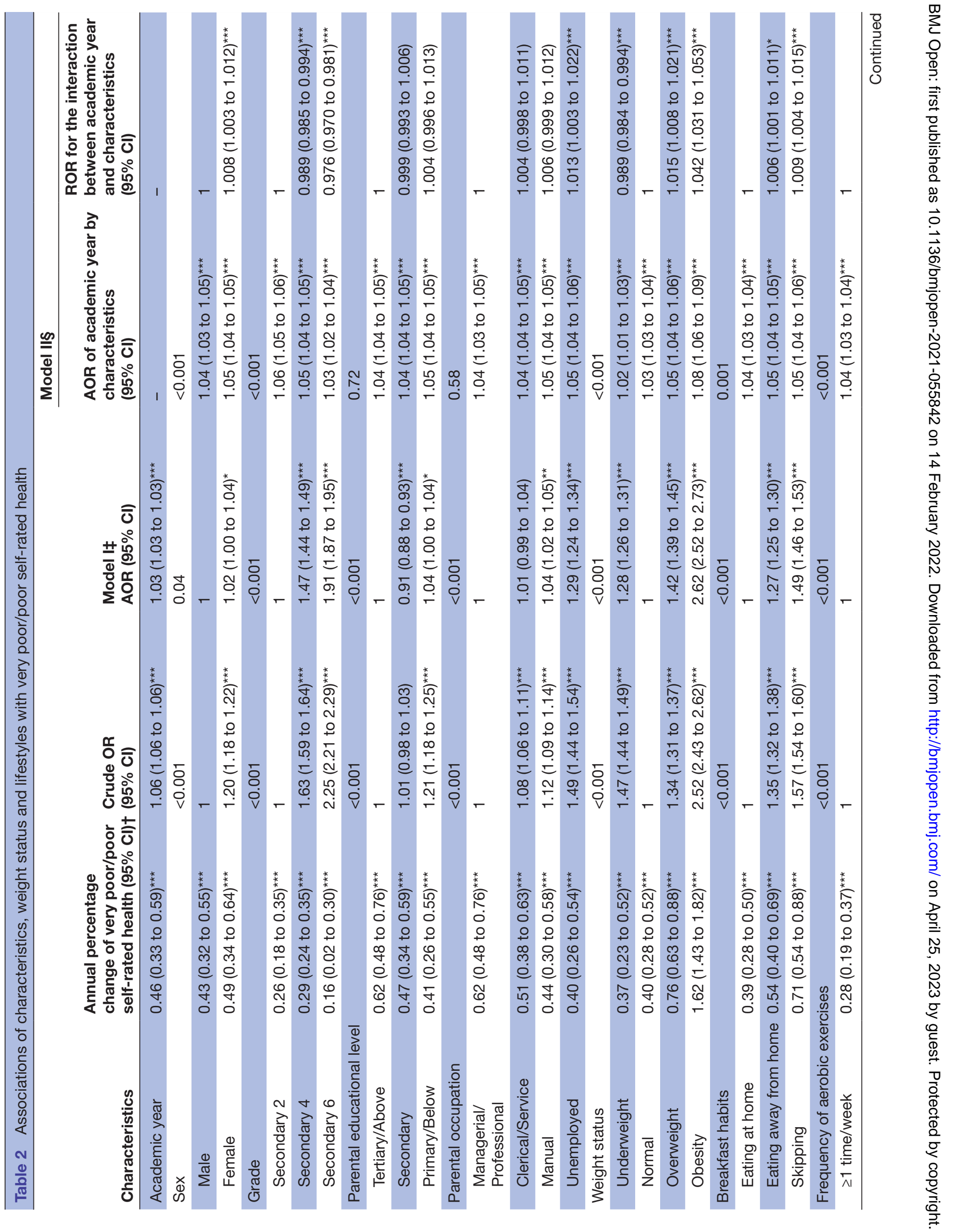




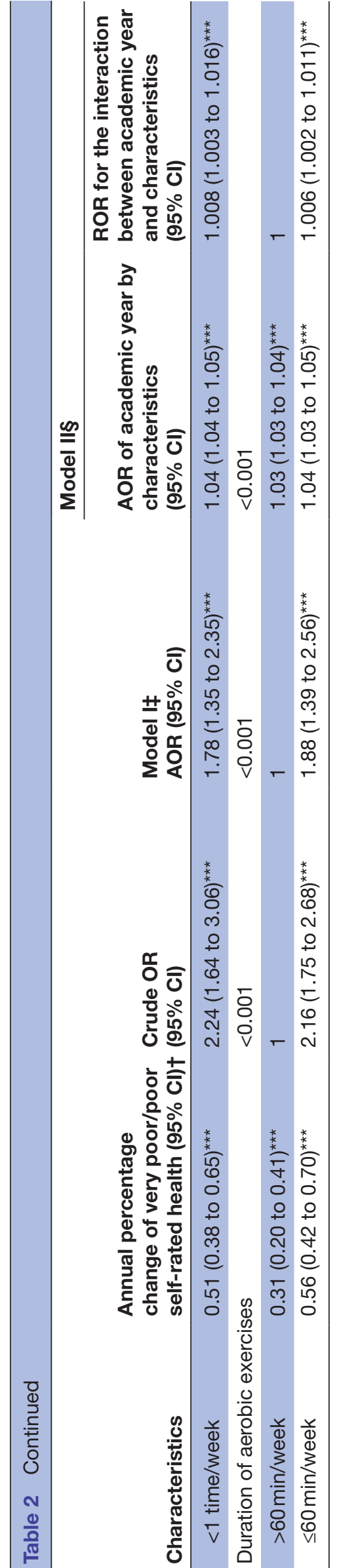

the world and steadily increased from 80.27 years in 1999 to 85.03 years in 2021 . However, the increasing very poor/ poor adolescent SRH could adversely affect well-being in later life and eventually shorten healthy life expectancy. Previous studies show that poor SRH in adolescence and young adulthood predict general practitioner consultations and mortality in later adulthood, which seemed to be not diseases-specific or organ-specific. ${ }^{27-29}$ Strategies should be taken to prevent the worsening trends in adolescent SRH to reduce future burden of diseases.

When compared with their normal-weighted peers, both underweight and overweight/obese adolescents had higher percentages of very poor/poor SRH, but the increases were smaller in those being underweight and greater in those being overweight/obese. The cultural preference to take thinness as the idealised beauty may encourage adolescents to regard underweight as healthier but to stigmatise obesity. The social stigma and negative views of obesity had been rising in young people over the past four decades. ${ }^{30}$ Adolescents with obesity may thus have more unpleasant experiences, including teasing and peer victimisation, and increasingly may enhance their body dissatisfaction and negative perception of health. ${ }^{31}$ Although people from different ethnic and racial backgrounds had the same aversion to overweight and obesity, ${ }^{32}$ more pressures and comparisons of body shape were found in Chinese media than in Western media, posing more body concerns in Chinese young people. ${ }^{33}$ From 1992 to 2007 , some national health surveys reported that obesity was increasingly associated with poorer adult SRH in Switzerland but not in Portugal and the USA. ${ }^{345}$ The normalisation of obesity and acceptance of diversity in some Western countries could have led to the weak association. ${ }^{34}$ Trends in adolescent SRH relating to weight status deserve further studies across different cultural background.

We first showed that sex disparity in SRH increased over time in Chinese adolescents, with a greater worsening trend in girls' SRH. In contract, the proportion of girls rating their health as excellent showed improvements in five Nordic countries during 2002-2014. ${ }^{10}$ Unfortunately, direct comparison cannot be made since different standard populations were used. Nevertheless, more attention on the SRH among Asian adolescents, especially girls would be desirable.

We found that very poor/poor SRH were increasingly more prevalent in adolescents having unhealthy lifestyles. Healthy lifestyles, including more aerobic exercises and home meals, were reported to be associated with better adolescent SRH, self-image and health-related quality of life. ${ }^{36-38}$ Conversely, those with good SRH had the selfidentity as being healthy, which promote them to adopt better health behaviours and maintain healthy lifestyles. ${ }^{28}$ Notably, although lifestyles and weight status in youth may have mutual effects and both are associated with socioeconomic status, ${ }^{39} 40$ we found breakfast habits, frequency and duration of physical exercise and weight status were still associated with trends in SRH after adjustment, which 
was consistent with previous findings. ${ }^{41}$ While socioeconomic status is relatively stable, lifestyles are cost-effective modifiable factors for enhancing adolescent health. ${ }^{11}$ Strategies to tackle health inequality should consider modifiable factors, including weight status and lifestyles, which may help to alleviate the growing socioeconomic disparities in health.

The worsening trend in adolescent SRH also raised concerns of the potential lagged influences of economic recession on adolescent SRH. The Asian economic crisis in 1997 caused the economic recession and rising suicide rates in Hong Kong in 1997/98. ${ }^{42}$ After that, Hong Kong had a short rapid economic recovery during 1999/2000, corresponding to the relative stationery of adolescent SRH during 1999/2000 to 2002/03. Due to the burst of international technology and Nasdaq bubble and the subsequent global economic slowdown in 2001, the recovery process in Hong Kong had been restrained and a tremendous economic contraction happened in 2001 again ${ }^{43}$ followed by the increase of very poor/poor SRH in adolescents since 2002/03. Moreover, the global financial crisis in 2008 triggered another economic recession in Hong Kong, which has been found to be associated with a significant increase in the risk of depression. ${ }^{44}$ Consistently, adolescent SRH showed a slightly increasingly worsen trend after 2008/09. Increases in parental divorce and unemployment are unavoidable attendant problems due to economic crisis, ${ }^{42}$ which may pose a long-term deleterious impact on young people's subjective health. ${ }^{45}$ Future studies may compare more population-based psychosocial health indicators before, during and after the global recession, which can help policymakers to identify and justify priorities of health promotion in the face of economic crisis.

This study had some limitations. First, we only used parental educational level and occupation as proxies of socioeconomic status. Although family income and perceived socioeconomic status have been found to be associated with $\mathrm{SRH},{ }^{46}$ they were not routinely collected in the health assessment scheme under the SHS thus were not considered in this study. Second, about $2.9 \%-4.4 \%$ of the enrolled secondary students were from international schools, who may not be Chinese although ethnicity was not recorded. ${ }^{47}$ However, as the prevalence was low, any effect on the results should be small. Third, although all items in SHS questionnaires were reported to have moderate test-retest reliability, ${ }^{48}$ lifestyles were obtained using single items, so recall bias and reporting bias would be unavoidable. Also, only three lifestyles were considered in this study, more lifestyles, including daily consumption of fruit and vegetables, daily sleep duration, screen use, drinking and smoking, were found to be jointly associated with SRH. ${ }^{37}$ So far, there is no consensus on how to define a healthy lifestyle. Lastly, no causal inferences could be made in this panel study.

\section{CONCLUSIONS}

The prevalence of very poor/poor SRH increased from 1999/2000 to 2014/15 in Hong Kong adolescents, which was greater in girls, adolescents being overweight/obese and those having unemployed parents or unhealthy lifestyles. Strategies to tackle health inequality should consider multiple factors, especially modifiable factors including lifestyles.

Acknowledgements We thank all colleagues and staff at the Student Health Service of the Department of Health for their assistance and collaboration.

Contributors WJG conceived and drafted the initial manuscript. DYTF developed the study methodology, interpreted the data, drafted the manuscript, and served as the guarantor. MPW and THL critically reviewed the manuscript. TWHC contributed to data collection and critically reviewed the manuscript. SYH designed the original study and critically reviewed the manuscript. All authors approved the final manuscript as submitted and agreed to be accountable for all aspects of the work.

Funding Health and Health Services Research Fund, Food and Health Bureau, Hong Kong SAR (05060781).

\section{Competing interests None declared.}

Patient consent for publication Not applicable.

Ethics approval The study protocol was approved by the Institutional Review Board of The University of Hong Kong/Hospital Authority Hong Kong West Cluster (reference number: UW 19-206) and the Department of Health Ethics Committees (reference number: L/M 66/2019). The study was carried out in accordance with the principles embodied in the Declaration of Helsinki. All participants' parents/ guardians gave written informed consent each year to enrol in the annual SHS health assessments, including the use of the participants' data for research.

Provenance and peer review Not commissioned; externally peer reviewed.

Data availability statement Data are available on reasonable request. Data may be obtained from a third party and are not publicly available. The data supporting the conclusions of this study are available from the Student Health Services, Department of Health, Hong Kong SAR, but restrictions apply to the availability of these data, which were used under agreement for the current study, and so are not publicly available. Data are however available from the authors on reasonable request and with permission of the Student Health Services, Department of Health, Hong Kong SAR.

Supplemental material This content has been supplied by the author(s). It has not been vetted by BMJ Publishing Group Limited (BMJ) and may not have been peer-reviewed. Any opinions or recommendations discussed are solely those of the author(s) and are not endorsed by BMJ. BMJ disclaims all liability and responsibility arising from any reliance placed on the content. Where the content includes any translated material, BMJ does not warrant the accuracy and reliability of the translations (including but not limited to local regulations, clinical guidelines, terminology, drug names and drug dosages), and is not responsible for any error and/or omissions arising from translation and adaptation or otherwise.

Open access This is an open access article distributed in accordance with the Creative Commons Attribution Non Commercial (CC BY-NC 4.0) license, which permits others to distribute, remix, adapt, build upon this work non-commercially, and license their derivative works on different terms, provided the original work is properly cited, appropriate credit is given, any changes made indicated, and the use is non-commercial. See: http://creativecommons.org/licenses/by-nc/4.0/.

\section{ORCID iDs}

Wei Jie Gong http://orcid.org/0000-0003-2410-7518

Daniel Yee Tak Fong http://orcid.org/0000-0001-7365-9146

Man Ping Wang http://orcid.org/0000-0003-4000-2388

\section{REFERENCES}

1 Jylhä M. What is self-rated health and why does it predict mortality? Towards a unified conceptual model. Soc Sci Med 2009;69:307-16.

2 DeSalvo KB, Jones TM, Peabody J, et al. Health care expenditure prediction with a single item, self-rated health measure. Med Care 2009;47:440-7.

3 Krause NM, Jay GM. What do global self-rated health items measure? Med Care 1994;32:930-42.

4 Vingilis E, Wade TJ, Adlaf E. What factors predict student self-rated physical health? J Adolesc 1998;21:83-97. 
5 Vingilis ER, Wade TJ, Seeley JS. Predictors of adolescent self-rated health. Can J Public Health 2002;93:193-7.

6 Richter M, Moor I, van Lenthe FJ. Explaining socioeconomic differences in adolescent self-rated health: the contribution of material, psychosocial and behavioural factors. J Epidemiol Community Health 2012;66:691-7.

7 Petersen AC, Leffert N, Graham B. Promoting mental health during the transition into adolescence. Health risks and developmental transitions during adolescence. New York, NY, US: Cambridge University Press, 1997: 471-97.

8 Riley AW. Evidence that school-age children can self-report on their health. Ambul Pediatr 2004:4:371-6.

9 Cavallo F, Dalmasso P, Ottová-Jordan V, et al. Trends in self-rated health in European and North-American adolescents from 2002 to 2010 in 32 countries. Eur J Public Health 2015;25(Suppl 2):13-15.

10 Potrebny T, Torsheim T, Due P, et al. Trends in excellent self-rated health among adolescents: a comparative Nordic study. Nordisk välfärdsforskning 2019;4:67-76.

11 Sargent-Cox K, Cherbuin N, Morris L, et al. The effect of health behavior change on self-rated health across the adult life course: a longitudinal cohort study. Prev Med 2014;58:75-80.

12 Osera T, Awai M, Kobayashi M, et al. Relationship between selfrated health and lifestyle and food habits in Japanese high school students. Behav Sci 2017;7:71.

13 Rose T, Barker M, Maria Jacob C, et al. A systematic review of digital interventions for improving the diet and physical activity behaviors of adolescents. J Adolesc Health 2017;61:669-77.

14 Deshmukh-Taskar PR, Nicklas TA, O'Neil CE, et al. The relationship of breakfast skipping and type of breakfast consumption with nutrient intake and weight status in children and adolescents: the National health and nutrition examination survey 1999-2006. J Am Diet Assoc 2010;110:869-78.

15 Affenito SG. Breakfast: a missed opportunity. J Am Diet Assoc 2007:107:565-9.

16 Giménez-Legarre N, Miguel-Berges ML, Flores-Barrantes $\mathrm{P}$, et al. Breakfast characteristics and its association with daily micronutrients intake in children and adolescents-a systematic review and metaanalysis. Nutrients 2020;12:3201.

17 Gong W-J, Fong DY-T, Wang M-P, et al. Skipping breakfast and eating breakfast away from home were prospectively associated with emotional and behavioral problems in 115,217 Chinese adolescents. J Epidemiol 2021:JE20210081.

182016 Population By-census Office. Hong Kong 2016 population bycensus report. Hong Kong, CN: Census and Statistics Department, 2017.

19 Schooling CM, Leung GM. A socio-biological explanation for social disparities in non-communicable chronic diseases: the product of history? J Epidemiol Community Health 2010;64:941-9.

20 Student Health Service. Enrolment forms and related information Hong Kong SAR: department of health, The Goverment of Hong Kong SAR, China. Available: https://www.studenthealth.gov.hk/ english/resources/resources_forms/resources_forms.html [Accessed 12 Apr 2021]

21 Cole TJ, Bellizzi MC, Flegal KM, et al. Establishing a standard definition for child overweight and obesity worldwide: international survey. BMJ 2000;320:1240-3.

22 Gong W-J, Fong DY-T, Wang M-P, et al. Increasing socioeconomic disparities in sedentary behaviors in Chinese children. BMC Public Health 2019;19:754.

23 Cohen J. A power primer. Psychol Bull 1992;112:155-9.

24 Education Bureau. Student enrolment statistics, 2018/19 (kindergarten, primary and secondary levels) Hong Kong, CN2019. Available: https://www.edb.gov.hk/attachment/en/about-edb/ publications-stat/figures/Enrol_2019.pdf [Accessed 05 May 2020].

25 Ballinger GA. Using generalized estimating equations for longitudinal data analysis. Organ Res Methods 2004;7:127-50.

26 Department of Health. Department of health annual report from 1999/2000 to 2014/15. Hong Kong, CN: Government Print: 2000-15.
27 Vie TL, Hufthammer KO, Meland E, et al. Self-rated health (SRH) in young people and causes of death and mortality in young adulthood. A prospective registry-based Norwegian HUNT-study. SSM Popul Health 2019;7:100364.

28 Hetlevik Øystein, Vie TL, Meland E, et al. Adolescent self-rated health predicts general practice attendance in adulthood: results from the Young-HUNT1 survey. Scand J Public Health 2019;47:37-44.

29 Idler EL, Benyamini Y. Self-rated health and mortality: a review of twenty-seven community studies. J Health Soc Behav 1997;38:21-37.

30 Cornette RE. The emotional impact of obesity on children. Global perspectives on childhood obesity. Elsevier, 2011: 257-64.

31 Herbozo S, Tantleff-Dunn S, Gokee-Larose J, et al. Beauty and thinness messages in children's media: a content analysis. Eat Disord 2004;12:21-34.

32 Maddox GL, Back KW, Liederman WR. Overweight as social deviance and disability. J Health Soc Behav 1968;9:287-98.

33 Jackson T, Jiang C, Chen $\mathrm{H}$. Associations between Chinese/Asian versus Western mass media influences and body image disturbances of young Chinese women. Body Image 2016;17:175-83.

34 Marques-Vidal P, Ravasco P, Paccaud F. Differing trends in the association between obesity and self-reported health in Portugal and Switzerland. data from national health surveys 1992-2007. BMC Public Health 2012;12:588.

35 Macmillan R, Duke N, Oakes JM, et al. Trends in the association of obesity and self-reported overall health in 30 years of the integrated health interview series. Obesity 2011;19:1103-5.

36 Kirkcaldy BD, Shephard RJ, Siefen RG. The relationship between physical activity and self-image and problem behaviour among adolescents. Soc Psychiatry Psychiatr Epidemiol 2002;37:544-50.

37 Marques A, Peralta M, Santos T, et al. Self-rated health and healthrelated quality of life are related with adolescents' healthy lifestyle. Public Health 2019;170:89-94.

38 Osera T, Awai M, Kobayashi M, et al. Relationship between selfrated health and lifestyle and food habits in Japanese high school students. Behav Sci 2017;7:71.

39 Burdette AM, Needham BL, Taylor MG, et al. Health lifestyles in adolescence and self-rated health into adulthood. $J$ Health Soc Behav 2017;58:520-36.

40 Gong W-J, Fong DY-T, Wang M-P, et al. Increasing socioeconomic disparities in sedentary behaviors in Chinese children. BMC Public Health 2019;19:1-10.

41 Krause L, Lampert T. Relation between overweight/obesity and selfrated health among adolescents in Germany. Do socio-economic status and type of school have an impact on that relation? Int $J$ Environ Res Public Health 2015;12:2262-76.

42 Chang S-S, Gunnell D, Sterne JAC, et al. Was the economic crisis 1997-1998 responsible for rising suicide rates in East/Southeast Asia? A time-trend analysis for Japan, Hong Kong, South Korea, Taiwan, Singapore and Thailand. Soc Sci Med 2009;68:1322-31.

43 Government of Hong Kong SAR. Half-yearly economic report 2007. Hong Kong, CN: Government Print, 2007.

44 Lee S, Guo W-J, Tsang A, et al. Evidence for the 2008 economic crisis exacerbating depression in Hong Kong. J Affect Disord 2010;126:125-33.

45 Roustit C, Campoy E, Renahy E, et al. Family social environment in childhood and self-rated health in young adulthood. BMC Public Health 2011:11:949.

46 Goodman E, Huang B, Schafer-Kalkhoff T, et al. Perceived socioeconomic status: a new type of identity that influences adolescents' self-rated health. J Adolesc Health 2007;41:479-87.

47 Census and Statistics Department. Hong Kong annual digest of statistics: government of Hong Kong SAR, China; 2009 and 2014 Available: https://www.statistics.gov.hk/pub/B10100032014AN14 B0100.pdf [Accessed 02 May 2020].

48 Tin SPP, Ho SY, Mak KH, et al. Location of breakfast consumption predicts body mass index change in young Hong Kong children. Int $J$ Obes 2012;36:925-30. 